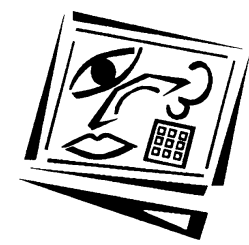

\title{
A multivariate analysis of students' experience of web based learning
}

\author{
Uschi Felix \\ Monash University
}

This paper reports on a large scale study carried out in four settings that investigates the potential of the web as a medium of language instruction, both to complement face to face teaching and as a stand alone course. Data was collected by questionnaires and observational procedures to ascertain student perceptions of the usefulness of web based learning, their views on its advantages and disadvantages, their personal comfort and enjoyment when working with the web, their preferred mode of delivery, their evaluation of the quality of resources used, and their learning strategies and study preference.

Results showed that students were on the whole positively inclined to working with the web and found it useful, with the majority preferring to use the web as an add on to face to face teaching. Reported advantages fell into the broad categories of time flexibility, reinforced learning, privacy and wealth of information; disadvantages into distraction, absence of teacher and personal interaction and lack of speaking practice. Significant differences for age and gender were found relating to clarity of objectives, number of hours worked, mode of delivery, perception of comfort and appreciation of graphics. Very few significant findings relating to strategy strength emerged.

\section{Introduction}

While a number of studies have investigated the role of the web in language learning, they have tended to concentrate on individual variables such as reading ability (Ganderton 1999), acquisition of grammar (Lamy 1997), elicitation tasks (Ayoun 2000), motivation and attitude (Atkinson 1998), discourse analysis (Warschauer 1996), or project based CALL (Meagher \& Castanos 1996, Debski \& Gruba 1998). No large scale multivariate investigation focussing on the students' experience of web based language learning has been reported to date. 
While findings in the above studies have on the whole been encouraging about the use of the web for language learning activities, there have also been strongly opposing voices in other fields (Hara \& Kling 1999, Noble 1997, 1998a, 1998b).

Where the effectiveness of web based learning is concerned, research is scarce and lacks scholarly rigour (Windschitl 1998, McIssac \& Gunawardana 1996), and the difficulty of generalising results prevalent in the previous generation of computer assisted learning (CAL) continues. In general, research into the efficacy of CAL has produced equivocal results (Dunkel 1991), and it is easy to list problems attached to such research (Chapelle 1997).

The present study has deliberately not attempted to investigate effectiveness in terms of achievement. Instead, it has concentrated on students' views on the web as a viable environment for language learning and has sought to examine the following aspects:

- How comfortable tertiary students feel about working in a web based environment.

- How enjoyable they find such an environment.

- Whether perceptions of comfort or enjoyment change after prolonged use.

- Whether students find it useful to work with web based materials.

- Which elements of the web resources they find most useful.

- How they perceive the advantages and disadvantages of web based learning over conventional learning.

- Which mode of delivery they prefer.

- Which strategy strengths typify good web based learners.

- Whether study preference - working alone or with others - makes a difference to perceptions.

- Whether distance learners have different perceptions from those who use web based materials as an add on to face to face teaching.

Given the general trend in the literature that suggests differential use of the online environment by males (Stewart et al 1999, Parry \& Wharton 1994, Smith 1995), and by younger students (Meredyth et al 1999), we also investigated potential differences in the perceptions of all variables relating to gender and age. 


\section{Method}

\section{Participants}

A number of colleagues identified as leaders in web based language teaching (Felix 1998) were invited to participate. Those who accepted the invitation were an online provider for beginners and intermediate Italian, based in New York, two universities in Melbourne, one teaching beginners Japanese and the other intermediate English as a Second Language (ESL), and a college of technical and further education also teaching intermediate/advanced ESL in Melbourne. The Melbourne students attended classes and had face to face contact with a teacher, using the web either in class or as an extra resource. The New York students were enrolled as distance learners. It would have been desirable to have a better balance of face to face and distance students but one committed partner withdrew at the last moment.

Seventy-five percent of the participants were female and $25 \%$ male, with ages ranging from 18 to 75 . A large variety of language backgrounds were represented, with 54\% specifying a language other than English as their native language.

\section{Materials used}

The online materials differed slightly between the three courses based in Melbourne, but were all designed to provide additional language practice in various forms ranging from specially written exercises with online feedback to task based activities using other linked sites [see Japanese as an example, http://www.arts.monash.edu.au/japanese/ocjpl1015/] The online Italian course, by contrast, was designed to teach everything exclusively online. It was therefore much more formally structured with more extensive materials provided at different levels of proficiency and had tutor contact through a chat site. [http:// cyberitalian.com/]

\section{Procedure}

The study was conducted during second semester 1999 over approximately 11 weeks. Students' consent to participate was sought through statements of intent that were handed out or emailed. Students were asked to complete three different questionnaires on three separate occasions online, using their own name or an alias. Video taped interviews were conducted with a random sample of 12 local students using an identical interview protocol. Questionaires can be viewed at: [http://www.arts.monash.edu.au/lc/sill_example/index.html] 


\section{Questionnaires}

1. Strategy Inventory for Language Learning (Oxford's SILL, Oxford 1990). This was completed at the start of teaching, before students had used the web materials. Results were intended to give a broad indication of students' strategy preferences/strength.

2. Web experience/perception questionnaire (designed by the author). This was completed after questionnaire 1 , after students had spent considerable time using the web materials.

3. Resource Evaluation (adapted from Kennedy's CAL evaluation, Kennedy 1998). This was completed last, after completion of the web activities. The intention was partly to provide a summative evaluation of the materials, but mainly to gauge students' impression of their quality. Given the trend in the literature that students react badly to the environment as a whole if resources are pedagogically unsound or technically unstable (Hara \& Kling 1999), this measure was designed to put comments made in response to the second questionnaire into perspective.

\section{Data analyses}

Univariate analyses of variance were used to identify any significant relationships between selected variables. Tukey HSD post hoc tests were then used on significant relationships to determine where the significant differences lay. Correlation analyses, nonparametric tests using two independent samples, and t-tests were also used where appropriate. Sixtythree valid responses (out of a total of 75 students enrolled) were received for the first and second questionnaires and 48 for the third. Most analyses reported below contain 63 subjects, while those related to quality of resources contain 48 . The major sample was distributed over $16 \%$ online Italian, 43\% Japanese, 40\% ESL. To conserve space, tables for statistical analyses are not included, but levels of significance (set at $\mathrm{p}<0.05$ ) are given on each occasion. The full documentation is available from the author.

\section{Results: Quantitative data}

\section{Mode of delivery and study preference}

Students were asked to rank on a 4 point scale four modes in which language learning materials might be used on the web: 
1. As an addition to face to face teaching used in the classroom.

2. As an addition to face to face teaching used in the students' own time.

3. As a distance learning resource used without access to an online tutor.

4. As a distance learning resource used with access to an online tutor.

Nearly half the respondents considered that the best way to use web materials was in class as an addition to face to face teaching, and the least preferred mode was distance learning without access to a tutor. Significant differences were found for the students enrolled in the distance learning course who had a greater preference for options $2(p=.009)$ and $4(p=.05)$ than the face to face learners and for non native speakers of English who had a greater preference for option 1 than native speakers $(p=.05)$.

On the question of study mode preference, only $21 \%$ of students chose to work alone, the rest preferring to work with a partner $(35 \%)$ or in a group $(44 \%)$.

\section{Comfort, enjoyment and usefulness}

Participants were asked to indicate on a five point Likert scale how true statements about feeling comfortable with, and enjoying learning on, the web were for them. While a large number of students were already comfortable with the web at the start of the study (57.2\% giving a score of 4 or 5), an even greater number were comfortable at the end of the study $(73.1 \%)$, with only $1.6 \%$ still feeling uncomfortable. More than half the participants enjoyed using the web at the start, but the improvement in enjoyment at the end of the study was not as dramatic as that for feeling comfortable, although there was a significant improvement especially at the lowest end of the scale which dropped from $17.5 \%$ to $3.2 \%$. The majority of students $(65.1 \%)$ also indicated that they found using the web for language learning useful (Table 1).

Table 1: Comfort, enjoyment and usefulness

\begin{tabular}{|l|c|c|c|c|c|}
\hline & $\begin{array}{c}\text { Comfortable } \\
\text { at start }\end{array}$ & $\begin{array}{c}\text { Comfortable } \\
\text { at end }\end{array}$ & $\begin{array}{c}\text { Enjoy at } \\
\text { start }\end{array}$ & $\begin{array}{c}\text { Enjoy at } \\
\text { end }\end{array}$ & Useful \\
\hline Never true & $17.5 \%$ & $1.6 \%$ & $17.5 \%$ & $3.2 \%$ & $1.6 \%$ \\
\hline Generally not true & $14.3 \%$ & $7.9 \%$ & $7.9 \%$ & $3.2 \%$ & $11.1 \%$ \\
\hline Somewhat true & $11.1 \%$ & $17.5 \%$ & $22.2 \%$ & $27.0 \%$ & $22.2 \%$ \\
\hline Generally true & $30.2 \%$ & $30.2 \%$ & $31.7 \%$ & $38.1 \%$ & $41.3 \%$ \\
\hline Always true & $27.0 \%$ & $42.9 \%$ & $20.6 \%$ & $28.6 \%$ & $23.8 \%$ \\
\hline
\end{tabular}


The improvement for both comfort and enjoyment was highly significant $(\mathrm{p}=.000)$. Another significant finding was that the distance learners felt even more comfortable $(p=.024)$. This is not surprising given that they had entered the environment of their own volition.

\section{Relationship between perception of comfort/enjoyment and usefulness}

The analysis showed a significant link between students finding the materials useful and feeling comfortable at the start $(\mathrm{p}=.012)$ and at the end $(p=.000)$ of the study, and enjoying using the web at the end of the study $(\mathrm{p}=.000)$. The relationship between usefulness and enjoyment at the start was not significant. What seems to follow from this is that there is an interest in making students comfortable - ensuring that everything works properly and that materials are enjoyable - and in sustaining their enjoyment.

\section{Relationship between comfort, enjoyment and length of study}

The analysis showed that the longer students had spent learning the language they were currently studying, the more comfortable they were using the web both at the start $(\mathrm{p}=.015)$ and at the end $(\mathrm{p}=.009)$ of the study period. They also enjoyed using the web from the beginning of the study period $(p=.045)$. Length of study of the language did not, however determine whether students enjoyed using the web by the end of the study period. These findings suggest that it is important to give special attention to beginning students in a subject. Personal observations confirm that students unsure of the subject matter feel less comfortable in computer based teaching environments.

\section{Evaluation of resource}

Participants were asked to evaluate various aspects of the programs they used for language learning rating them on a scale from 1 to 5 or 1 to 9 . Tables $2 a$ and $2 b$ show the frequency of their average responses which were calculated by summing the responses for each category and dividing by the number of questions for that category. While results were presented in detail to the developers for summative evaluation only broad findings are reported here. Responses were very favourable, ranging from $73 \%$ to $90 \%$ agreeing or strongly agreeing that the objectives were clear, the content was logical, the program was interactive and the navigation easy. Some $75 \%$ to $94 \%$ rated the quality of the text, graphics, sound and 
interface as 6 or above on a scale of 1-9. (The text category needs to be reversed since lower ratings represent readability).

Table $2 \mathrm{a}$

\begin{tabular}{|l|c|c|c|c|c|c|c|c|}
\hline & \multicolumn{2}{|c|}{$\begin{array}{c}\text { Objectives / } \\
\text { directions }\end{array}$} & \multicolumn{2}{c|}{$\begin{array}{c}\text { Content and } \\
\text { structure }\end{array}$} & \multicolumn{2}{l|}{ Interactivity } & \multicolumn{2}{c|}{ Navigation } \\
\hline & Freq & $\%$ & Freq & $\%$ & Freq & $\%$ & Freq & $\%$ \\
\hline Strongly disagree & 1 & 2.1 & 0 & 0 & 0 & 0 & 1 & 2.1 \\
\hline Disagree & 2 & 4.2 & 0 & 0 & 2 & 4.2 & 0 & 0 \\
\hline Neutral & 8 & 16.7 & 5 & 10.4 & 11 & 22.9 & 11 & 22.9 \\
\hline Agree & 28 & 58.3 & 32 & 66.7 & 29 & 60.4 & 28 & 58.3 \\
\hline Strongly agree & 9 & 18.8 & 11 & 22.9 & 6 & 12.5 & 8 & 16.7 \\
\hline Total & 48 & 100.0 & 48 & 100.0 & 48 & 100.0 & 48 & 100.0 \\
\hline
\end{tabular}

Table $2 b$

\begin{tabular}{|c|r|r|r|r|r|r|r|r|}
\hline & \multicolumn{2}{|c|}{ Text } & \multicolumn{2}{c|}{ Graphics } & \multicolumn{2}{c|}{ Sound } & \multicolumn{2}{c|}{ Interface } \\
\hline & Freq & \multicolumn{1}{|c}{$\%$} & Freq & \multicolumn{1}{c|}{$\%$} & Freq & \multicolumn{1}{c|}{ Freq } & $\%$ \\
\hline Low 3 & 1 & 2.1 & 3 & 6.4 & 1 & 2.1 & 0 & 0 \\
\hline 4 & 3 & 6.3 & 3 & 6.4 & 4 & 8.3 & 0 & 0 \\
\hline 5 & 18 & 37.5 & 6 & 12.8 & 7 & 14.6 & 3 & 6.4 \\
\hline 6 & 18 & 37.5 & 13 & 27.7 & 3 & 6.3 & 19 & 40.4 \\
\hline 7 & 7 & 14.6 & 9 & 19.1 & 10 & 20.8 & 13 & 27.7 \\
\hline 8 & 1 & 2.1 & 10 & 21.3 & 14 & 29.2 & 7 & 14.9 \\
\hline High 9 & 0 & 0 & 3 & 6.4 & 9 & 18.8 & 5 & 10.6 \\
\hline Total & 48 & 100.0 & 47 & 100.0 & 48 & 100.0 & 47 & 100.0 \\
\hline
\end{tabular}

An analysis of which aspects of the web materials contributed to the perception of their usefulness showed that the most important elements were clear and logically organised content $(p=.004)$, clear objectives $(p=.013)$, meaningful feedback $(\mathrm{p}=.008)$, and easy navigation through the program $(\mathrm{p}=$ $.039)$.

\section{Relationship between number of hours spent on the web and other variables}

Participants spent between 5 and 50 hours working with the web materials. A large percentage (39\%) worked for about 10 hours, while a small number (10\%) spent more than 40 hours online. Non-native speakers of English spent significantly more hours online than the native speakers $(p=.000)$. The more comfortable respondents were at the start of the study period, the more hours they spent using the web materials $(p=.024)$. They also 
spent more time using the program if they rated highly clarity of objectives $(\mathrm{p}=.006)$, or the quality of the graphics $(\mathrm{p}=.040)$. The findings related to graphics are particularly interesting in the light of the fact that students did not find materials more useful if they enjoyed the graphics (see above). However, if they are prepared to spend more hours working with web materials as a result of good graphics, this has clear design implications.

\section{Language learning strategies used}

Students were asked a series of questions relating to the strategies they used when learning a new language. For each strategy they were given a score out of five. With the exception of Memory and Affective strategies, well in excess of $80 \%$ of participants clustered around the midpoint, scoring between 3 and 4 for each category. While over $80 \%$ of students scored between 3 and 4 for Memory strategies, this category differed from the others because $75 \%$ scored 3 . The least favoured strategy was the affective one with a much larger percentage (37.5\%) scoring 2 (Table 3). However, scores for this strategy were significantly higher for the non-native speakers of English $(\mathrm{p}=.000)$.

Table 3: Language learning strategies used

\begin{tabular}{|c|c|c|c|c|c|c|}
\hline Memory & Cognitive & $\begin{array}{c}\text { Compens } \\
\text {-ation }\end{array}$ & $\begin{array}{c}\text { Metacog- } \\
\text { nitive }\end{array}$ & Score & Affective & Social \\
\hline $0 \%$ & $0 \%$ & $2.0 \%$ & $2.0 \%$ & 1 & $8.3 \%$ & $2.0 \%$ \\
\hline $16.3 \%$ & $10.2 \%$ & $4.1 \%$ & $4.1 \%$ & 2 & $37.5 \%$ & $8.2 \%$ \\
\hline $75.5 \%$ & $44.9 \%$ & $49.0 \%$ & $55.1 \%$ & 3 & $45.8 \%$ & $44.9 \%$ \\
\hline $8.2 \%$ & $42.9 \%$ & $40.8 \%$ & $36.7 \%$ & 4 & $8.3 \%$ & $40.8 \%$ \\
\hline $0 \%$ & $2.0 \%$ & $4.1 \%$ & $2.0 \%$ & 5 & $0 \%$ & $4.1 \%$ \\
\hline
\end{tabular}

\section{Relationship between language learning strategies and other variables}

Analyses were conducted to investigate the differences in the ratings of usefulness, enjoyment and level of comfort with web learning as they related to the different learning strategies used. The analysis did not support the hypothesis that certain learning strategy strengths will have an effect on the way language students perceive web learning.

There was, however, a significant relationship between study preference and use of affective strategies ( $\mathrm{p}=.007)$. Those with low affective strategies preferred to work alone, those with medium affective strategies preferred to 
work with one other person, and those with high affective strategies preferred to work in a group.

\section{Relationship between age and other variables}

For analysis purposes students were divided into two groups: those younger than 30 and those older than 30. Nonparametric tests using two independent samples showed that the younger students were more comfortable with the web at the start $(\mathrm{p}=.001)$ and more impressed with the graphics $(p=.002)$. The older students preferred the option of using the web out of class hours as an addition to face to face teaching $(p=.000)$, had been studying the language for a longer period of time $(p=.007)$, and spent more time using the web materials $(p=.000)$. These findings appear to support the commonly held view that younger people respond well to graphics. They also support current statistics that show the highest use of the Internet in Australia by 30-49 year olds (Roy Morgan Research). The reason for this may well be that this group has easiest access to the online environment.

\section{Relationship between gender and other variables}

Analysis of variance showed three significant differences between males and females. Males spent longer using the web than females $(p=.000)$; had a greater preference for the face to face option with the web materials to be used in class $(p=.009)$; and rated clarity of objectives more highly $(p=.002)$. While the first finding supports the general trend in the literature, the other two are difficult to interpret. Perhaps males - who are certainly a minority of language learners - are less confident and prefer the extra support provided by a teacher, and have lower demands on what constitutes a clear objective. There is material here for further investigation.

\section{Results: Qualitative data}

Participants were asked to identify what they saw as the main advantages and disadvantages of using web based programs for language learning. Those who identified advantages (60) outnumbered those who saw disadvantages (35), although many identified both. To conserve space we have categorised answers into representative headings; full transcripts are available from the author. 
Advantages (60)

- Time flexibility

- Wealth of information

- Reinforcement of learning

- Privacy

- Ability to repeat exercises

- Gaining computer literacy

- Absence of teacher (3)

An interesting aspect of comments on teachers was that while 10 respondents found that lack of teachers was a disadvantage, 3 found it to be a positive advantage:

- I have no desire to deal one on one with professors and their petty little egos or tests.

- Don't have personal contact with the teacher. A computer doesn't talk back.

- The computer is more patient than any teacher could ever be.

The videotaped interviews supported the views expressed in the questionnaires and confirmed the overall positive attitude towards using web materials as an adjunct to face to face teaching. The most interesting observation was of a mature age male student who had in this short space of time gone from "being scared of computers" and being close to computer illiterate to "being in love" with his computer and having published four short stories on the web.

\section{Discussion}

Judging from the overall responses, there can be no doubt that the web is a viable environment for language learning, especially as an add on to face to face teaching.

The somewhat surprising support for using the web in class rather than independently should be read in the context of the fact that $43 \%$ of the students had used this option. These findings appear to corroborate the results of another study (Felix 2000) which suggests that students tend to prefer the option they are used to rather than considering other possible solutions. This is further supported here in the preference expressed by distance learners for distance education or for using materials on their own. This clearly suggests that students' motivation for learning in distance mode may play an important role in their judgment of the environment. Students who have voluntarily enrolled in a course offered 
by distance tend to be highly motivated and are likely to cope well in isolation. By contrast, online learning was not something our face to face learners were expecting, and there has been substantial anecdotal evidence that university students resent online learning if they see it as a cost cutting exercise. The strong wish to preserve the traditional classroom environment may well be a reaction to that. Another possible explanation is that language students may need more immediate support from a teacher. The fact that the highest ratings for this option came from male students and non-native speakers of English, both traditionally less confident language learners in Australia, lends some support to this view.

What can be concluded, however, is that responses on the whole were overwhelmingly positive. This finding needs to be seen in the context of the resources themselves being very highly rated. Another group, originally committed to participate in the study, pulled out at the last moment because the students were so frustrated with technical difficulties that they refused to take part. Had they been included, results relating to comfort, enjoyment and usefulness would have looked dramatically different (Hara \& Kling 1999). In fact, two mature age women struggling with the materials in the computer laboratory became so disheartened by the combination of their own computer illiteracy and the instability of the resources that they claimed to have lost all interest in studying the language. While there will always be students who resist technology (Felix 2000), such severe reactions can at least be avoided by proper testing and trialling of programs before they are introduced for student use. This is particularly important if assessment is to be included.

As it turned out in this study, students reported high levels of comfort and enjoyment while working with web materials, although some $17 \%$ reported feeling uncomfortable to begin with. Not surprisingly, distance learners and younger students felt significantly more comfortable and beginners significantly less so. This suggests that attention needs to be given to proper induction sessions for students new to the subject (this had not been the case in the group that dropped out). A very encouraging finding was that levels of comfort and enjoyment improved significantly over the course of the study period - something that refutes speculations about a novelty component in the use of technology in learning environments. From experience, students tend to persist with activities they find useful, especially when they are linked to what is needed for exams and assessments. The fact that they also rated the materials as useful may explain this finding. 
Few surprises emerged in the case of the particular elements that influenced students' perception of the material's usefulness. They found the resources most useful if the objectives were clear, the content clear and logically organised, the feedback useful, and navigation easy, supporting good practice design principles. The fact that there was no relation between the quality of sound and graphics and perception of usefulness was unexpected, but may have to do with the fact that all the ratings were very high. Had these elements been rated below average, it may well have influenced how useful students found the program. Their perception of usefulness was also significantly affected by the fact that students felt comfortable at the start and at the end of the study, and were still enjoying the experience at the end. These findings appear to support the view that making students comfortable and the learning experience enjoyable may have salutary outcomes (Felix \& Lawson 1994).

One significant finding related to feelings of comfort was that students were prepared to spend more hours working with the materials. The other elements contributing to this outcome were the quality of the graphics and the clarity of the objectives. Gender, age and language background also contributed to the time spent studying online, with males, older students and non-native speakers of English using the materials for significantly more hours. A reason for this could again be a lack of confidence in this group, or it may be that mature age and non-native speakers are more diligent, and that males spend more time on computers. If the latter is true, the inclusion of computer based learning might be a useful motivating source to attract more males to language studies.

Very few findings related to language learning strategies and study preference emerged. Strategy use was fairly evenly distributed over the categories with the exception of affective strategies which were the least favoured overall, especially for native speakers of English. Preference for these strategies was also highly correlated with a preference for working in groups. It is therefore not surprising that no significant relationship between strategy strength and perception of the environment was found for the group as a whole. It was surprising, however, that no other relationships relating to study preference were established when it might be assumed that online environments lend themselves especially to students who prefer to learn on their own. However, the fact that only $16 \%$ of participants actually worked on their own may have confounded results somewhat. 
As to the perceived advantages and disadvantages of the environment, students reported fairly traditional and well rehearsed views. It is difficult to ascertain whether these were specifically linked to the particular resource they had been using or to their general perception of the environment. What is interesting to note, however, is the large skew towards advantages. While aspects such as time flexibility, reinforcement of learning, privacy ("the computer does not judge you"), gaining computer literacy and the ability to repeat exercises have equally been mentioned as advantages in the previous generation of $\mathrm{CAL}$, an added element here was wealth of information. This new environment offers students the unique ability to set off instantaneously on task based journeys to authentic settings or to gain information on almost anything they need without leaving their computer.

On the other hand, this advantage also leads to the newly articulated disadvantage of distraction, which was not something particularly mentioned during the CD-ROM era. The other disadvantages - lack of speaking practice, absence of teacher, no interaction with peers and inadequate feedback - are not unique to the web environment but used to be common complaints in technology based language learning. What is encouraging about the new technologies is that all of these can be addressed more easily now. Incorporating web phone or voice recognition software may help with speaking practice, and there is no reason why students cannot speak to each other as part of the learning process especially in collaborative local settings (Debski \& Gruba 1998). The presence of the teacher is also now fostered more easily through, for example, discussion groups, chats and MOOs.

\section{Conclusion}

The message from this research project is strongly encouraging. Students involved in web based learning not only have high levels of enjoyment and comfort, but these levels increase over time and perceptions of advantages significantly outnumber disadvantages. It is important to note, however, that results here were undoubtedly influenced by the high quality of the programs that were delivered, both in terms of their design and in the clarity and usefulness of their objectives. The group that pulled out because they could not cope with what they were offered obviously sends a very different message. 
An important requirement, therefore, is to trial the material first to ensure that it is delivered from the start at a high level of quality and robustness. It would also be sensible to pay particular attention to helping students new to the environment and the subject to come to terms with what can be a challenging experience, since these are the users most at risk of finding the environment less satisfactory.

Naturally even the best web based learning is unlikely ever to replace best practice face to face teaching, but what is becoming more and more obvious with emerging research is that the new technologies offer excellent potential for adding value to classroom teaching in a large variety of ways. Granted that in conducive conditions students find the experience enjoyable and useful and are prepared to work longer hours, it is highly probable that there may be better learning outcomes associated with the technology. The effect on achievement is therefore the next important question for the research to investigate.

\section{References}

Atkinson, T. (1998). Researching language learning and technology. Paper delivered at the inaugural WorldCALL conference, Melbourne, July 1998. [abstract verified 16 Mar 2001 at http: / / hlc.unimelb.edu.au/worldcall/str1.html\#1p2]

Ayoun, D. (2000). Web-based elicitation tasks in SLA research. Language Learning and Technology, 3(2), 77-98. [verified 16 Mar 2001]

http:/ /llt.msu.edu/vol3num2 / ayoun/index.html

Basena, D. and Jamieson, J. (1996). CALL Research in Second Language Learning: 1990-1994. CAELL, 7(1/2), 14-22.

Chapelle, C. (1997). CALL in the year 2000: Still in search of research paradigms? Language Learning and Technology 1(1), 19-43. [verified 16 Mar 2001] http: / /llt.msu.edu/vol1num1/ chapelle/ default.html

Debski, R. and Gruba, P. (1998). Attitudes towards language learning through social and creative computing. In K.C. Cameron (ed), Multimedia CALL: Theory and Practice. Proceedings of the Exeter 1997 Conference, Exeter: Elm Bank Publications, 51-56.

Dunkel, P. (1991). The effectiveness of research on computer-assisted instruction and computer-assisted langauge learning. In P. Dunkel (Ed), Computer-Assisted Language Learning and Testing. New York: Newbury House, 5-36.

Felix, U. and Lawson, M. (1994). The effects of suggestopedic elements on quantitative and qualitative language production. Australian Review of Applied Linguistics, 17(2), 1-21.

Felix, U. (1998). Virtual Language Learning: Finding the Gems among the Pebbles. Melbourne: Language Australia Ltd. 
Felix, U. (2000). The potential of CD-ROM technology for integrating language and literature: student perceptions. German as a Foreign Language, Issue 2 [verified 10 Apr 2001] http: / / www.schmachtenberg.de/gfl/ download / felix.doc

Ganderton, R. (1999). Interactivity in L2 Web-Based Reading. In Debski, R \& Levy, M. (Eds.), WorldCALL: Global perspectives on Computer-Assisted Language Learning, Amsterdam: Swets \& Zeitlinger, 49-66.

Hara, N. and Kling, R. (1999). Students' frustrations with a web-based distance education course. http:/ / firstmonday.org/issues/issue4_12/hara/ [verified 16 Mar 2001]

Kennedy, G.E. (1998). Computer Aided Learning: Formative evaluation questionnaires. Biomedical Multimedia Unit, University of Melbourne.

Lamy, M-N. (1997). The web for French grammar: A tool, a resource or a waste of time? ReCALL, 9(2), 26-32. [verified 16 Mar 2001] In: http: / / www.eurocall.org/recall/ rvol9no2.pdf

McIssac, M.S, Gunawardana, C.N. (1996). Distance education. In D. Johnassen (ed). Handbook of Research for Educational Communications and Technology. New York: Macmillan, 403-437.

Meagher, M.E. and Castanos, F. (1996). Perceptions of American culture: The impact of an electronically-mediated cultural exchange program on Mexican high school students. In S.C. Herring (Ed), Computer-Mediated Communication: Linguistic, Social and Cross-Cultural Perspectives, John Benjamins Company, Amsterdam.

Meredyth, D., Russel, N., Blackwood, L., Thomas, J. and Wise, P. (1999). Real Time. Computers, Change and Schooling, Department of Education, Training and Youth Affairs, Canberra.

Noble, D.F (1997). Digital Diploma Mills, part I, The automation of higher education. [verified 16 Mar 2001] http: / / communication.ucsd.edu/dl/ddm1.html

Noble, D.F. (1998a). Digital Diploma Mills, part II, The coming battle over online instruction. [verified 16 Mar 2001] http: / / communication.ucsd.edu/dl/ddm2.html

Noble, D.F. (1998b). Digital Diploma Mills, part III, The bloom is off the rose. [verified 16 Mar 2001] http: / / communication.ucsd.edu/dl/ddm3.html

Oxford, R. (1990). Language Learning Strategies: What Every Teacher Should Know. New York: Newbury House.

Parry L. and Wharton R, (1994). Networking in the workplace: the role of gender in electronic communications. In U. Gattiker (Ed), Studies in technological innovation and Human resources: vol. 4. Women and Technology, Berlin: DeGruyter Press, 6592. 
Smith, J. (1995). What does convergence mean for women? Intermedia, 23(5), 20-22.

Stewart, C.M, Shields, S.F, Monolescu, D. and Taylor J.C. (1999). Gender and participation in synchronous CMC: An IRC case study. Interpersonal Computing and Technology, 7(1-2). [verified 16 Mar 2001]

http: / www.emoderators.com/ipct-j/ 1999/n1-2/ stewart.html

Warschauer, M. (1996). Computer-mediated collaborative learning: Theory and practice. Modern Language Journal, 18(4), 470-481.

Windschitl, M. (1998). The WWW and classroom research: What path should we take? Educational Researcher, 27(1), 28-33.

Professor Uschi Felix is Associate Dean (Educational Technologies) in the Faculty of Arts at Monash University in Melbourne. She has a research background in applied linguistics, has been a lecturer in French and German, and during the last decade her work has focussed on the systematic integration into the curriculum of tested resources from stand-alone software to WWW sites. She has contributed to the development of multimedia software and websites in several languages, published many articles in international journals on the use of technology in language teaching, and her book Virtual Language Learning: Finding the Gems among the pebbles has become a bestseller for Language Australia.

Email: Uschi.Felix@arts.monash.edu.au 